\title{
REMARK ON THE PAPER OF K. MURALI AND K. M. NAGARAJA
}

\section{ALFRED WITKOWSKI}

Abstract. We show that the result of K. Murali and K. M. Nagaraja is not correct.

Mathematics subject classification (2010): 26D15.

Keywords and phrases: mean, Schur convexity.

\section{REFERENCES}

[1] K. Murali And K. M. Nagaraja, Schur convexity of Stolarsky's extended mean values, J. Math. Inequal. 10, 3 (2016), 725-735.

[2] A. W. Marshall And I. Olkin, Inequalities: Theory of Majorization and Its Applications, Academic Press, New York, 1979. 